\title{
Ungulates rely less on visual cues, but more on adapting movement behaviour, when searching for forage
}

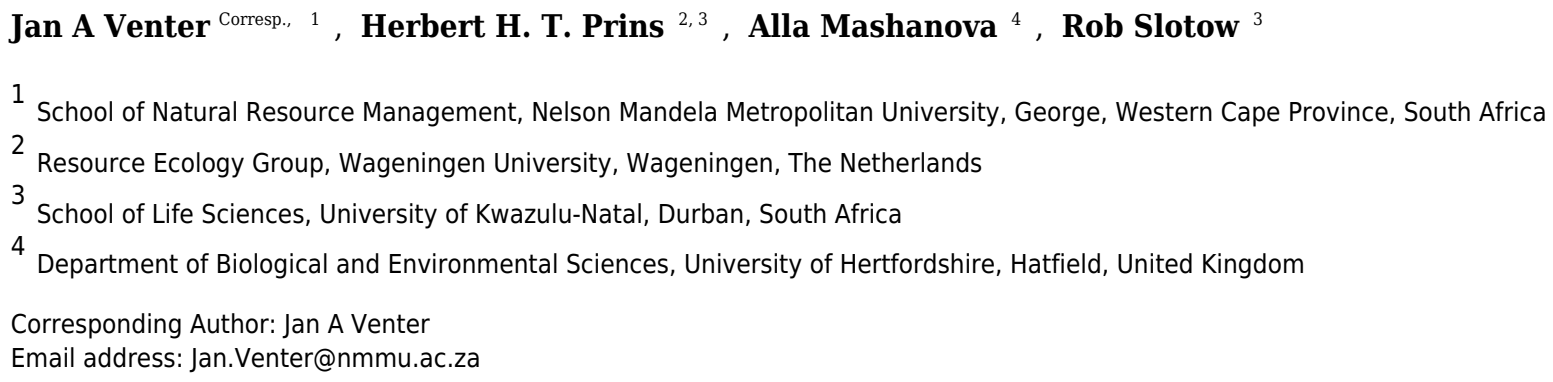

Finding suitable forage patches in a heterogeneous landscape, where patches change dynamically both spatially and temporally could be challenging to large herbivores, especially if they have no a priori knowledge of the location of the patches. We tested whether three large grazing herbivores with a variety of different traits, improve their efficiency when foraging at a heterogeneous habitat patch scale, by using visual cues to gain a priori knowledge about potential higher value foraging patches. For each species (zebra (Equus burchelli), red hartebeest (Alcelaphus buselaphus subspecies camaa ) and eland ( Tragelaphus oryx )), we used step lengths and directionality of movement to infer whether they were using visual cues to find suitable forage patches at a habitat patch scale. Step lengths were significantly longer for all species when moving to non-visible patches than to visible patches, but all movements showed little directionality. Of the three species, zebra movements were the most directional. Red hartebeest had the shortest step lengths and zebra the longest. We conclude that these large grazing herbivores may not exclusively use visual cues when foraging at a habitat patch scale, but would rather adapt their movement behaviour, mainly step length, to the heterogeneity of the specific landscape. 
1 Ungulates rely less on visual cues, but more on adaptive movement behaviour, when

2 searching for forage

3

$4{ }^{1}$ School of Natural Resource Management, George Campus, Nelson Mandela Metropolitan 5 University, Private Bag X6531, George, 6530, South Africa.

$6{ }^{2}$ School of Life Sciences, University of Kwazulu-Natal, Westville Campus, Private Bag X54001, 7 Durban, 4000, South Africa.

$8{ }^{3}$ Resource Ecology Group, Wageningen University, Droevendaalsesteeg 3a, 6705PB Wageningen, 9 The Netherlands

$10{ }^{4}$ Department of Biological and Environmental Sciences, University of Hertfordshire, Hatfield, 11 AL10 9AB, United Kingdom.

12

\section{ABSTRACT}

14 Finding suitable forage patches in a heterogeneous landscape, where patches change dynamically 15 both spatially and temporally could be challenging to large herbivores, especially if they have no 16 a priori knowledge of the location of the patches. We tested whether three large grazing 17 herbivores with a variety of different traits, improve their efficiency when foraging at a

18 heterogeneous habitat patch scale, by using visual cues to gain a priori knowledge about 19 potential higher value foraging patches. For each species (zebra (Equus burchelli), red hartebeest 20 (Alcelaphus buselaphus subspecies camaa) and eland (Tragelaphus oryx)), we used step lengths 21 and directionality of movement to infer whether they were using visual cues to find suitable 
22 forage patches at a habitat patch scale. Step lengths were significantly longer for all species when

23 moving to non-visible patches than to visible patches, but all movements showed little

24 directionality. Of the three species, zebra movements were the most directional. Red hartebeest

25 had the shortest step lengths and zebra the longest. We conclude that these large grazing

26 herbivores may not exclusively use visual cues when foraging at a habitat patch scale, but would

27 rather adapt their movement behaviour, mainly step length, to the heterogeneity of the specific

28 landscape.

29

30 


\section{INTRODUCTION}

32 African ecosystems are well known for their exceptional diversity of large mammalian

33 herbivores, of which a large proportion are ruminant bovids with a few non-ruminant equids

34 (Grange et al. 2004). The feeding type, body size and mouth morphology of large herbivores are

35 intrinsic constraints on the habitat that they can effectively use, and provide an understanding as

36 to how one species may be more or less constrained than another in a particular set of

37 environmental conditions. Different species of large herbivores may use a range of different

38 behaviours to enhance their foraging efficiency (Bailey et al. 1996; Beekman \& Prins 1989).

39 Finding a forage patch in a heterogeneous landscape where patches differ in suitability poses a

40 challenge, especially if individuals have no a priori knowledge of the location of the most

41 suitable patches (Bailey et al. 1996; Prins 1996; Senft et al. 1987). Large herbivores may gain a

42 priori knowledge using memory (from a previous visit to the patch) (Brooks \& Harris 2008;

43 Dumont \& Petit 1998; Edwards et al. 1996; Fortin 2003) or through visual cues (Edwards et al.

44 1997; Howery et al. 2000; Renken et al. 2008). If the forage resource is complex (e.g., when

45 forage patches are not well defined), or the distribution of the forage patches are likely to change

46 continuously (e.g., when a patch is grazed or the grass sward becomes unpalatable due to

47 ageing), then recalling the location of forage patches may be of limited value (Edwards et al.

48 1997). In such situations, heterogeneous in both space and time, the ability to recognise and

49 assess different forage patches at a distance through visual cues, would promote foraging success

50 (Edwards et al. 1997). An alternative behaviour to the use of visual cues would be adaptive

51 search/movement behaviour (Benhamou 2007; Benhamou \& Collet 2015; Martin et al. 2015). In

52 heterogeneous environments, adaptive movement, at different scales of step lengths and

53 directionality, e.g., a small-scale area-restricted search (within patches) mixed with a set of large 
54 more directional movements (between patches), can be a better search approach than an

55 approach of using visual cues, especially when the forage resource is complex and in constant 56 fluctuation.

58 A number of studies of forage patch location or re-visitation in large herbivores have linked 59 movement patterns to the use of memory (Brooks \& Harris 2008; Ramos-Fernandez et al. 2003) or visual cues at finer scales (e.g., bite, feeding station, and food-patch scales) (Howery et al.

61 2000; Laca 1998). However it is not clear whether large herbivores use visual cues to find forage 62 patches at a broader habitat patch scale. Our definition of habitat patch scale, adapted from 63 Owen-Smith (2010) and Bailey et al., (1996), refers to a daily range at a 10-hour temporal scale 64 while feeding, walking, drinking and resting, with movement within and between habitats. . We 65 tested whether three grazing herbivore species use visual cues when foraging at the habitat patch 66 scale. The selection of species represented differences in intrinsic traits (differences in body size, 67 feeding type, digestive system and muzzle width) which presumably would influence their 68 interaction with forage resources, e.g. search behaviour.

69 Red hartebeest are considered to be predominantly selective grazers that will make use of browse 70 under limited resource conditions (Kilian, 1993; Murrey, 1993). They are medium-sized (150 kg, 71 average of both sexes) ruminants with a preference for grass. In Mkambati Nature Reserve, South 72 Africa (our study area, hereafter referred to as Mkambati) they use $87 \% \mathrm{C}_{4}$ grasses (Venter \& 73 Kalule-Sabiti 2016). In areas with much moribund vegetation, grazing ruminants such as the red

74 hartebeest face particular constraints because nearly all vegetation biomass has a low quality, 75 which reduces food intake rates (Drescher et al. 2006a; Drescher et al. 2006b; van Langevelde et 
76 al. 2008). The hartebeest is an example of a concentrate selector; its muzzle width and length is

77 specially adapted (long and narrow) to be very selective at times when good forage is scarce

78 (Schuette et al. 1998). Eland are considered to be mixed feeders preferring browse (Hofmann \&

79 Stewart 1972; Watson \& Owen-Smith 2000) and in Mkambati their diet consist of $79 \% \mathrm{C}_{3}$ forage

80 (Venter \& Kalule-Sabiti 2016). They are ruminants with a large body size (511 kg, average of both

81 sexes)(Venter et al. 2014b). Zebra are non-ruminants and they are much more tolerant to poor

82 quality forage but must maintain a high rate of intake to be able to survive on this type of food

83 (Bell 1971; Okello et al. 2002; van Soest 1982). They are mainly grazers with their diet consisting

84 of $89 \% \mathrm{C}_{4}$ grasses in Mkambati (Venter \& Kalule-Sabiti 2016). They are medium sized (235 kg,

85 average male and female) equids (Venter et al. 2014b) with a wide muzzle classifying them as

86 bulk grazers (Bell 1971).

87

88 We developed and tested predictions based on directionality (an indication if a number of turning 89 angles, i.e. the absolute angle between movement $i$ and movement $i+1$, from a series of

90 movements are uniform, i.e. highly concentrated in one direction, or not), step length (distance

91 between two consecutive fixes from GPS telemetry data), and success (outcome of the search

92 movement, whether animals landed up in better forage or not) under three patch visibility

93 classes. In particular, we expected more directional movements with longer step lengths when

94 animals moved to visible patches and less directional movements with shorter step lengths to

95 non-visible patches. We expected, if animals used visual cues, that there would be longer step

96 lengths which are more directional when they move to better forage, because they could

97 anticipate success. No difference in step length or directionality when comparing the outcome of

98 movements (successful and not successful) would indicate that visual cues are not used at this 
99 particular scale because then the animal did not adapt the movement (walking straight towards a

100 observed patch) to anticipated success to find better forage. Due to the different intrinsic

101 constraints different species of ungulates have to deal with, we expected that each species would

102 approach its forage search strategy in different ways regardless of the use of visual cues or not or

103 because one species could be using visual cues more than another. Demonstrating a difference in

104 movement behaviour between visible and invisible habitat patches, and successful or not

105 successful movements would enable an understanding of the importance of visual cues to

106 different large herbivore species when moving between patches at a habitat patch scale.

107

108 METHODS

109 Study area

110 Mkambati is a $77 \mathrm{~km}^{2}$ provincial nature reserve situated on the east coast of the Eastern Cape

111 Province, South Africa ( $31^{\circ} 13^{\prime}-31^{\circ} 20^{\prime} \mathrm{S}$ and $\left.29^{\circ} 55^{\prime}-30^{\circ} 04^{\prime} \mathrm{E}\right)$. The climate is mild sub-tropical

112 with a relatively high humidity (de Villiers \& Costello 2013). The coastal location, adjacent to

113 the warm Agulhas Current, causes minimal variation in mean daily temperatures $\left(18{ }^{\circ} \mathrm{C}\right.$ winter

114 and $22{ }^{\circ} \mathrm{C}$ summer) (de Villiers \& Costello 2013). The average rainfall is $1200 \mathrm{~mm}$, with most

115 precipitation in spring and summer (September -February) (Shackleton 1990). The high rainfall,

116 mild temperatures, and presence of abundant streams and wetlands provide a landscape that is

117 not water-limited in any season. More than $80 \%$ of Mkambati consists of Pondoland-Natal

118 Sandstone Coastal Sourveld grassland (Mucina et al. 2006). Forests occur in small patches

119 (mostly in fire refuge areas)(Mucina et al. 2006). Mkambati contains a range of large herbivore

120 species, but no large predators (Venter et al. 2014b). 
122 The grassland is considered to be nutrient poor (Shackleton et al. 1991; Shackleton \& Mentis

123 1992). Grassland fire stimulates temporary regrowth high in crude protein (8.6\% compared to

$1244.6 \%$, in older grassland), phosphorus concentrations $(0.1 \%$ compared to $0.05 \%$, in older

125 grassland) and dry matter digestibility (38.6\% compared to $27.1 \%$, in older grassland)

126 (Shackleton 1989). Nutrient concentrations remain elevated for up to 6 months post-burn, after

127 which they are comparable to surrounding, unburnt grassland (Shackleton \& Mentis 1992).

128 Frequent fires cause a landscape mosaic of nutrient-rich burnt patches within a matrix of older,

129 moribund grassland. This landscape is thus continuously changing due to new fires that are set

130 and the maturing process of the grassland. Recalling the location of grazing forage patches

131 (using memory) would in this case be of limited value which enabled us to test predictions of

132 movement behaviour relative to visibility of forage patches.

133

\section{Data collection}

135 Five plains zebra (Equus burchelli) (4 female and 1 male), six red hartebeest (Alcelaphus

136 buselaphus subspecies camaa) (5 females and 1 male) and five eland (Tragelaphus oryx) (3

137 females and 2 males) were fitted with GPS-UHF collars (Africa Wildlife Tracking CC., Pretoria,

138 RSA) between September 2008 and July 2012. These species represented a range of intrinsic

139 constraints which could potentially influence their foraging strategies and subsequent search

140 movement behaviour (Venter \& Kalule-Sabiti 2016; Venter et al. 2014a; Venter et al. 2015). All

141 animals were darted by an experienced wildlife veterinarian from a Robinson 44 helicopter. The

142 work was approved by, and conducted in strict accordance with the recommendations in the 
143 approved standard protocols of the Animal Ethics Sub-committee of the University of KwaZulu-

144 Natal (Approval number 012/09/Animal). All field work was conducted by, or under the

145 supervision of the first author, while he was a staff member of the Eastern Cape Parks and

146 Tourism Agency, as part of the operational activities of the appointed management authority of

147 Mkambati (Eastern Cape Parks and Tourism Agency Act no. 2 of 2010, Eastern Cape Province,

148 South Africa). The zebra and red hartebeest were in separate harems or herds when they were

149 collared, but some eland ( 2 females) were in the same herd. The collars were set to take a GPS

150 reading every $30 \mathrm{~min}$, and data were downloaded via UHF radio signal. The collars remained

151 functional between 4 and 16 months depending on various factors, including loss of animals to

152 poaching, natural mortality, or malfunctioning. Data downloaded from the collars were

153 converted to geographical information system (GIS) format and sections of the data sets with

154 missing values were removed and not used in the analysis.

155

156 Step lengths (the distance travelled between each 30 min GPS fix) were calculated for each

157 “walk" using the Hawths Analysis Tools extension (Beyer 2007) to ArcGIS (ArcGIS Desktop:

158 Release 10. Redlands, CA: Environmental Systems Research Institute). Walks were extracted per

159 species (Eland $n=312$; Red hartebeest $n=309$; Plains zebra $n=279$ ). A walk consisted of 20

160 consecutive steps lengths which constituted 10 hours of movement behaviour during daylight

161 hours (6:00AM to 6:00PM) (Figure 1). Ten hours of movement represented movement between

162 patches at a habitat patch scale. To confirm whether ten hours of movement were indeed within a

163 realistic distance range for the habitat patch scale in our situation, we compared the mean

164 distance between patches to the mean animal walk distances per species. Starting points for each

165 walk were randomly selected (by day), with the visibility from the starting point of each walk 
166 being determined using the "viewshed analysis tool" in the Spatial Analyst extension of ArcGIS

167 (ArcGIS Desktop: Release 10. Redlands, CA: Environmental Systems Research Institute). This 168 resulted in a grid map (raster) layer that indicated all areas that were visible and not visible to 169 the animal from that specific starting point at its shoulder height (female shoulder height: eland $170 \bar{x}=1500 \mathrm{~mm}$ (Posselt 1963); red hartebeest $\bar{x}=1250 \mathrm{~mm}$ (Stuart \& Stuart 2007); plains zebra $\bar{x}$ $171=1338 \mathrm{~mm}($ Skinner \& Chimimba 2005)) (Figure 1). The end point was defined by the patch 172 where the animal spent the majority ( $\geq 50 \%$ ) of the final $3 \mathrm{~h}$ (7 locations) of the "walk" (Figure 173 1). All patches in the landscape were allocated a unique number, and classified as either burnt 174 grassland (fire patches) or unburnt grassland (unburnt patches) (Figure 1). The location of the 175 fire patches were recorded by field rangers between January 2007 and July 2012, and later 176 digitally defined on maps using ArcGIS. Each GPS locality along a "walk" was linked to a patch 177 classification using the Spatial Analyst extension of ArcGIS (ArcGIS Desktop: Release 10.

178 Redlands, CA: Environmental Systems Research Institute). All unburnt areas (areas that were 179 never noted as burnt between January 2007 and July 2012) were considered as one unburnt 180 patch, and was given the same unique identification number. The "walks" were then classified 181 into three different visibility classes which could be a movement: (a) to within the same patch 182 where the starting point was located; (b) to a new patch that was visible from the starting point; 183 and (c) to a new patch not visible from the starting point.

184 When an animal, at the end of a walk, ended up in, a) a better forage patch we considered the 185 movement as successful; b) the same we considered it as no change; and c) worse patch we 186 considered it as unsuccessful. Forage quality was better in recently burnt ( $<6$ months post fire) 187 grassland, see Shackleton \& Mentis (1992), compared to older grassland. All step lengths $<6 \mathrm{~m}$ 
188 were excluded during analysis in order to remove non-movements, as well as false movements

189 due to GPS-error.

190

\section{Data analysis}

192 We tested whether there was excessive variability amongst individual animal walk distances, 193 which could potentially influence the models, by comparing mean walk distance for different 194 species to inter-patch distances using visual inspection of box plots. This was done using IBM 195 Corp. Released 2014. IBM SPSS Statistics for Windows, Version 23.0. Armonk, NY.

196 We used the Rayleigh test of circular uniformity from CircSTats package in R (R-Development197 Core-Team 2011) to calculate the mean resultant length $r$ for each individual "walk". This 198 parameter $r$ provided a measure of the concentration of turning angles ranging between 0 and 1

199 (Duffy et al. 2011). When $r$ is close to 1, data are highly concentrated in one direction, and when 200 it is close to 0, data are widely dispersed (Duffy et al. 2011). The Rayleigh test provides p-values 201 associated with $r$ to test whether it is reasonable to reject angle uniformity. When $r \geq 0.5$ and the $202 p$-value indicated significance $(p<0.05)$, walks were considered to be concentrated in one 203 direction (directional).

204 We used a linear mixed model (LMM) to assess the effect of a number of factors on mean step 205 length per "walk". The fixed effects were species, visibility class and search outcome (success). 206 The random effect was individual animal. Wald test was used to determine whether variation in 207 step length between individuals was significant and should be included as a random effect. We 208 did not include interactions between the fixed effects as they were not significant when included 
209 in the model. Therefore, we used post-hoc pairwise comparisons with a Bonferroni correction to

210 determine differences in the main effects (IBM SPSS Statistics for Windows, Version 23.0.).

211

\section{RESULTS}

213 Median walk distances for red hartebeest $2120 \mathrm{~m}$ (1305-3068 m), eland $3328 \mathrm{~m}$ (2374-4341 m)

214 and zebra $3771 \mathrm{~m} 3771 \mathrm{~m}(2255-6755 \mathrm{~m})$ were similar to distances between patches $4994 \mathrm{~m}$

$215(2978-7371 \mathrm{~m})($ values in brackets give the first and the third quartiles), indicating that walks

216 represented movements at a landscape scale as defined by (Bailey et al. (1996)and Owen-Smith et 217 al. (2010) (Figure 2).

218 A low proportion of walks in each visibility class were directional for red hartebeest (6\% to not 219 visible; $3 \%$ to visible; and $8 \%$ within visible) and eland (7\% to not visible; $0 \%$ to visible; and $5 \%$

220 within visible)(Figure 3). Zebra had a higher proportion of directional walks (12\% to not visible;

$221 \quad 17 \%$ to visible; and 17\% within visible) than eland and red hartebeest (Figure 3).

222 A linear mixed model with step lengths as dependant variable, success, visibility class and 223 species as fixed effects, and animal ID as a random effect suggests that all fixed effects are 224 significant ( $\mathrm{p}$ - values $0.045,<0.0005$ and 0.005 , respectively). The Wald test suggests that there 225 is a significant variation in step length between individuals $(P=0.026)$. We therefore kept 226 animal ID in the model as a random factor. With search movement outcome, the difference 227 between "no change" versus both "successful" and "not successful" were marginally significant $228(\mathrm{p}=0.054$ and $\mathrm{p}=0.074$, respectively) (Table 1, Figure 4A). Zebra had significantly longer step 229 lengths than red hartebeest $(\mathrm{p}=0.005)$ and approached significance for eland $(\mathrm{p}=0.06)($ Table 1 , 230 Figure 4B). The difference between eland and hartebeest was not significant $(\mathrm{p}=0.69)($ Table 1 , 
231 Figure 4B). For visibility classes, step lengths in the "within visible" and "to visible" classes

232 were not different ( $\mathrm{p}=0.37)$, but the step lengths for both these categories were significantly

233 shorter than step lengths to "not visible" classes ( $\mathrm{p}=0.002$ and $\mathrm{p}<0.0005$ respectively) (Table 1 ,

234 Figure 4B).

235

\section{DISCUSSION}

237 In our study we observed little directional movement when animals (from all species) moved to

238 visible patches, which supports a view that large herbivores do not rely exclusively on visual

239 cues when moving to search for patches at a habitat patch scale. Our results support the

240 simulations by Benhamou (2007) which showed that, in patchy environments adaptive

241 movements combining small-scale area-restricted searches (within good forage patches) and

242 large directional movements between patches (in our case, movement to forage patches which

243 were not visible), were used as an optimal strategy to search for habitat patches. However we did

244 not observe a clear pattern in the directionality of the movements (more directional movements

245 between patches) which could indicate that our study animal's strategy could potentially not be

246 as optimal a search strategy compared to the Benhamou (2007) simulations.

247 During fine scale search modes at the bite, feeding station and food patch scale, as defined by

248 Owen-Smith et al. (2010), animals would make use of visual and olfactory cues to find suitable

249 forage items (Edwards et al. 1997; Laca 1998). At coarser scales (e.g. habitat patch scale),

250 herbivores would randomly move, with larger step lengths until they are able to detect more

251 suitable forage (at the finer scale). The search patterns displayed by our study animals thus

252 indicate an adaption of their movement to the patchiness of the environment rather than long and 
253 directional step lengths, as expected if visual cues (or the lack thereof) had played a major role

254 (Benhamou 2007; Benhamou \& Collet 2015). Adaptations of animal movement behaviour to

255 patchiness at the habitat scale, has been observed elsewhere (de Knegt et al. 2007; Duffy et al.

256 2011), and is confirmed by this study.

257 Red hartebeest had the shortest step lengths of the three study species. Red hartebeest is an 258 example of a concentrate selector; its skull morphology is specially adapted to be very selective 259 at times when good forage is scarce (Schuette et al. 1998). In areas with much moribund 260 vegetation, grazing ruminants such as the red hartebeest face particular constraints because 261 nearly all vegetation biomass has a low quality, which reduces food intake rates (Drescher et al. 262 2006a; Drescher et al. 2006b; van Langevelde et al. 2008). By being more selective, hartebeest 263 would probably need to have more spatially complex movement scales. Red hartebeest, being the 264 smaller ruminant (compared to eland), needing less, but better quality, forage to meet their 265 nutritional and energy requirements (Demment \& Soest 1985; Illius \& Gordon 1992), used a 266 strategy where they foraged using smaller and less directional steps (compared to zebra), whether 267 they were moving within patches or to visible patches, but increased their step lengths when 268 moving to invisible patches, just like zebra and eland. The smaller step lengths could be 269 explained by their tendency to move slower and spend more time in less nutritious patches which 270 was observed by Venter et al. (2014a). They could thus be more effective in extracting more 271 nutritious material from older moribund grass tufts (due to their adapted muzzle) and therefore 272 be moving in shorter more concentrated steps. In addition, because they are ruminants, they 273 probably spend a significant amount of time ruminating, and moving less, compared to a non274 ruminant such as zebra. 
276 Eland had shorter step lengths than zebra but slightly larger step lengths than red hartebeest.

277 Eland is one of the larger African ruminant species and is considered to be a selective feeder

278 (which includes browse) that require a diet of high nutritive value, low fibre and high protein

279 content (Arman \& Hopcraft 1975). In Mkambati they primarily use browse and make little use of

280 grass as forage (Venter \& Kalule-Sabiti 2016). They also have a relatively small rumen in

281 relation to their body size and retain food in the rumen for a shorter time (shorter compared to

282 cattle), which allowing for a greater consumption rate (compared to hartebeest) (Arman \&

283 Hopcraft 1975). Zebra (non-ruminant) and eland (ruminant) have different body sizes but have

284 similar digestive capacity due to differences in their digestive system (Demment \& Soest 1985).

285 It is, therefore, surprising that eland has shorter step lengths than zebra. . This behaviour could

286 possibly be linked to their diet, as being able to browse they can overcome the challenge of

287 dealing with a landscape of nutrient poor, moribund grassland by eating forbs and trees (when

288 available). Forbs are common, especially in newly burned patches in Mkambati (Shackleton

289 1989). Because trees a resource that does not change as rapidly as continuously burnt grassland,

290 eland should be able to return to browsing patches using memory. This could possibly explain

291 their movement behaviour, although one would have expected more directional movements if

292 memory were being used.

293 Zebra used larger step lengths and had more directional walks (although still a small proportion

294 of their walks), compared to the eland and hartebeest. These variations could be linked to

295 differences in the species intrinsic traits, such as digestive system, muzzle width and body weight

296 (Prins \& Van Langevelde 2008; Senft et al. 1987). Zebra, a non-ruminant, is less efficient at

297 digesting food and has to maintain a higher intake-rate to maintain its energy requirements (Bell

298 1971; Demment \& Soest 1985; Illius \& Gordon 1992). This should cause them to move more 
299 frequently from one food patch to another as food patches are depleted due to grazing (Bell 300 1971). In addition, they have a wider muzzle than the two ruminant species which makes them 301 capable of using very short grass swards (which are common in recently burned grass patches).

302 Zebra have been shown to prefer newly burned grassland (Sensenig et al. 2010), but they are 303 forced to keep moving to new food patches because the lower biomass in a given patch is 304 depleted much more quickly (Venter et al. 2014a). In addition, the overall higher directionality 305 of zebra movement could indicate that they are more efficient in finding new forage patches. 306 Both these factors would cause movements with larger step lengths and more directionality, as 307 we observed with this species.

308 There is a certain degree of uncertainty whether walk directionality was affected by the step 309 length. Hurford (2009) showed that GPS measurement errors might lead to reporting overly 310 tortuous movement when the distances between locations were smaller than $20 \mathrm{~m}$. Although we 311 removed all distances smaller than $6 \mathrm{~m}$ from the analysis there is a chance that part of our turning 312 angle measurements were affected by GPS error. For example, larger proportion of short steps in 313 hartebeest might explain why directionality in hartebeest movements was smaller than we 314 expected.

315 Our study provides some evidence indicating that large grazers might not exclusively rely on 316 visual cues when foraging at a habitat patch scale, but rather adapt their search mode, mainly 317 longer step lengths, when they move to invisible patches. The animals used this adaptive 318 approach to foraging to cope with continuously changing forage conditions. In addition, it shows 319 that different species search for forage in different ways, which could indicate that search 320 strategies are linked to intrinsic traits such as body size, feeding type, digestive strategy and 321 muzzle width. 
322

\section{ACKNOWLEDGEMENTS}

324 Mkambati Nature Reserve staff, students from the University of Kwazulu-Natal and students

325 from Pennsylvania State University, Parks and People program for providing field assistance.

326 


\section{REFERENCES}

328

329

330

331

332

333

334

335

336

337

338

339

340

341

342

343

344

345

346

347

348

349

350

351

352

353

354

355

356

357

358

359

360

361

362

363

364

365

366

367

368

369

370
Arman P, and Hopcraft D. 1975. Nutritional studies on East African herbivores. British Journal of Nutrition 33:255-264.

Bailey DW, Gross JE, Laca EA, Rittenhouse LR, Coughenour MB, Swift DM, and Sims PL. 1996. Mechanisms that result in large herbivore grazing distribution patterns. Journal of Range Management 49:386-400.

Beekman JH, and Prins HHT. 1989. Feeding strategies of sedentary large herbivores in East Africa, with emphasis on the African buffalo, Syncerus caffer. African Journal of Ecology 27:129-147.

Bell RHV. 1971. A grazing ecosystem in the Serengeti. Scientific American 225:86-93.

Benhamou S. 2007. How many animals really do the Lévy walk? Ecology 88:19621969.

Benhamou S, and Collet J. 2015. Ultimate failure of the Lévy Foraging Hypothesis: Two-scale searching strategies outperform scale-free ones even when prey are scarce and cryptic. Journal of Theoretical Biology 387:221-227.

Beyer HL. 2007. Haw's Analysis Tools for ArcGIS. 3.27 ed.

Brooks CJ, and Harris S. 2008. Directed movement and orientation across a large natural landscape by zebras, Equus burchelli antiquorum. Animal Behaviour 76:277-285.

de Knegt HJ, Hengeveld GM, van Langevelde F, de Boer WF, and Kirkman KP. 2007. Patch density determines movement patterns and foraging efficiency of large herbivores. Behavioral Ecology 18:1065-1072.

de Villiers D, and Costello J. 2013. Mkambati and the Wild Coast, Second edition. Port St Johns, South Africa: Div deVilliers and John Costello

Demment MW, and Soest PJV. 1985. A nutritional explanation for body-size patterns of ruminant and nonruminant herbivores. The American Naturalist 125:641-672.

Drescher M, HeitkÃ-nig IMA, Van Den Brink PJ, and Prins HHT. 2006a. Effects of sward structure on herbivore foraging behaviour in a South African savanna: An investigation of the forage maturation hypothesis. Austral Ecology 31:76-87.

Drescher M, Heitkönig IMA, Raats JG, and Prins HHT. 2006b. The role of grass stems as structural foraging deterrents and their effects on the foraging behaviour of cattle. Applied Animal Behaviour Science 101:10-26.

Duffy KJ, Dai X, Shannon G, Slotow R, and Page B. 2011. Movement patterns of African elephants (Loxodonta africana) in different habitat types. South African Journal of Wildlife Research 41:21-28.

Dumont B, and Petit M. 1998. Spatial memory of sheep at pasture. Applied Animal Behavior Science 60:43-53.

Edwards GR, Newman JA, Parsons AJ, and Krebs JR. 1996. The use of spatial memory by grazing animals to locate food patches in spatially heterogeneous environments: an example with sheep. Applied Animal Behaviour Science 50:147-160.

Edwards GR, Newman JA, Parsons AJ, and Krebs JR. 1997. Use of cues by grazing animals to locate food patches: an example with sheep. Applied Animal Behaviour Science 51:59-68. 
371 Fortin D. 2003. Searching behavior and use of sampling information by free-ranging

372 bison (Bos bison). Behavioral Ecology and Sociobiology 54:194-203.

373

374

375

376

377

378

379

380

381

382

383

384

385

386

387

388

389

390

391

392

393

394

395

396

397

398

399

400

401

402

403

404

405

406

407

408

409

410

411

412

413

414

415

Grange S, Duncan P, Gaillard J-M, Sinclair ARE, Gogan PJP, Packer C, Hofer H, and Marion E. 2004. What limits the Serengeti zebra population? Oecologia 140:523532.

Hofmann RR, and Stewart DRM. 1972. Grazer or browser: a classification based on the stomach-structure and feeding habitats of East African ruminants. Mammalia 36:226-240.

Howery LD, Bailey DW, Ruyle GB, and Renken WJ. 2000. Cattle use visual cues to track food locations. Applied Animal Behaviour Science 67:1-14.

Illius AW, and Gordon IJ. 1992. Modeling the nutritional ecology of ungulate herbivores: Evolution of body size and competitive interactions. Oecologia 89:426-434.

Laca EA. 1998. Spatial memory and food searching mechanisms of cattle. Journal of Range Management 51:370-378.

Martin J, Benhamou S, Yoganand K, and Owen-Smith N. 2015. Coping with spatial heterogeneity and temporal variability in resources and risks: Adaptive movement behaviour by a large grazing herbivore. PLOS ONE 10:e0118461.

Mucina L, Scott-Shaw CR, Rutherford MC, Camp KGT, Matthews WS, Powrie LW, and Hoare DB. 2006. Indian Ocean Coastal Belt. In: Mucina L, and Rutherford MC, eds. The Vegetation of South Africa, Lesotho and Swaziland. Pretoria: South African Biodiversity Institute.

Okello MM, Wishitemi REL, and Muhoro F. 2002. Forage intake rates and foraging efficiency of free-ranging zebra and impala. South African Journal of Wildlife Research 32:93-100.

Owen-Smith N, Fryxell JM, and Merrill EH. 2010. Foraging theory upscaled: the behavioural ecology of herbivore movement. Philosophical Transactions of the Royal Society 365:2267-2278.

Posselt J. 1963. Domestication of the eland. Rhodesian Journal of Agricultural Research 1:81-87.

Prins HHT. 1996. Behavior and Ecology of the African Buffalo: Social Inequality and Decision Making. London: Chapman \& Hall.

Prins HHT, and Van Langevelde F. 2008. Resource Ecology. New York: Springer.

R-Development-Core-Team. 2011. R: A language and environment for statistical computing. Vienna: R Foundation for Statistical Computing.

Ramos-Fernandez G, Mateos JL, Miramobtes O, Cocho G, Larralde H, and AyalaOrozco B. 2003. Levy walk patterns in the foraging movements of spider monkeys (Ateles geoffroyi). Behavioral Ecology and Sociobiology 55:223-230.

Renken WJ, Howery LD, Ruyle GB, and Enns RM. 2008. Cattle generalise visual cues from the pen to the field to select initial feeding patches. Applied Animal Behaviour Science 109:128-140.

Schuette JR, Leslie DM, Lochmiller RLJ, and Jenks JA. 1998. Diets of hartebeest and roan antelope in Burkina Faso: Support of the long-faced hypothesis. Journal of Mammalogy 79:426-436.

Senft RL, Coughenour MB, Bailey DW, Rittenhouse LR, Sala OE, and Swift DM. 1987. Large herbivore foraging and ecological hierarchies. BioScience 37:789-799. 
416 Sensenig RL, Demment MW, and Laca EA. 2010. Allometric scaling predicts preferences for burned patches in a guild of East African grazers. Ecology 91:2898-2907.

Shackleton CM. 1989. An ecological survey of a selected area of Pondoland Sourveld with emphasis on its response to the management practices of burning and grazing Masters Degree Thesis. University of Transkei.

Shackleton CM. 1990. Seasonal changes in biomass concentration in three coastal grassland communities in Transkei. Journal of the Grassland Society of South Africa 7:265-269.

Shackleton CM, Granger JE, Mcenzie B, and Mentis MT. 1991. Multivariate analysis of coastal grasslands at Mkambati Game Reserve, north-eastern Pondoland, Transkei. Bothalia 21:91-107.

Shackleton CM, and Mentis MT. 1992. Seasonal changes in nutrient content under three defoliation treatments in two coastal grassland communities of Transkei. Tydskrif van die Weidingsvereniging van Suid Afrika 9:30-37.

Skinner JD, and Chimimba CT. 2005. The Mammals of the Southern African Subregion. New York: Cambridge University Press.

Stuart C, and Stuart T. 2007. Field guide to Mammals of southern Africa. Cape Town: Struik Publishers.

van Langevelde F, Drescher M, Heitkönig IMA, and Prins HHT. 2008. Instantaneous intake rate of herbivores as function of forage quality and mass: Effects on facilitative and competitive interactions. Ecological Modelling 213:273-284.

van Soest PJ. 1982. Nutritional ecology of the ruminant. Corvallis: OB Booksa.

Venter JA, and Kalule-Sabiti MJ. 2016. Diet composition of the large herbivores in Mkambati Nature Reserve, Eastern Cape, South Africa. African Journal of Wildlife Research 46:49-56.

Venter JA, Nabe-Nielsen J, Prins HT, and Slotow R. 2014a. Forage patch use by grazing herbivores in a South African grazing ecosystem. Acta Theriologica 59:457-466.

Venter JA, Prins HHT, Balfour DA, and Slotow R. 2014b. Reconstructing grazer assemblages for protected area restoration. PLoS ONE 9:e90900.

Venter JA, Prins HHT, Mashanova A, de Boer WF, and Slotow R. 2015. Intrinsic and extrinsic factors influencing large African herbivore movements. Ecological Informatics 30:257-262.

Watson LH, and Owen-Smith N. 2000. Diet composition and habitat selection of eland in semi-arid shrubland. African Journal of Ecology 38:130-137. 
Figure 1

A hypothetical example of a "walk" extracted for the study

Walks were extracted from the data which included the departure point (indicated by "Start") to where the animal ended (indicated by "End"). Here the animal hypothetically spent the majority of the last three hours of its "walk" in an area which was not visible from the starting point (indicated by grey). The striped area indicates a recent fire patch.

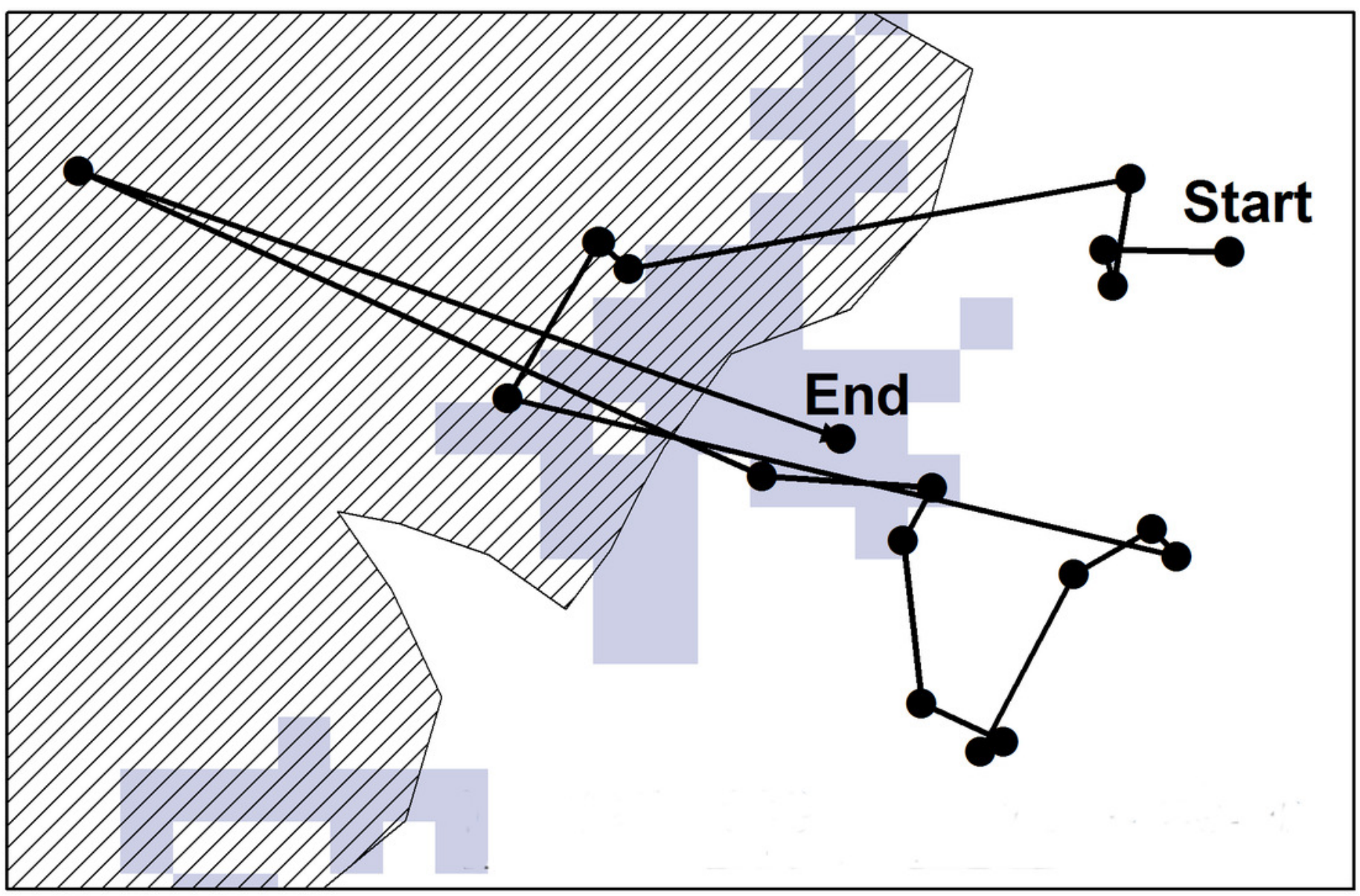


Figure 2

Mean +/- 1 S.D. $(m)$ of inter-patch distances and distances moved in a 10-h walk by red hartebeest, eland and zebra in Mkambati Nature Reserve

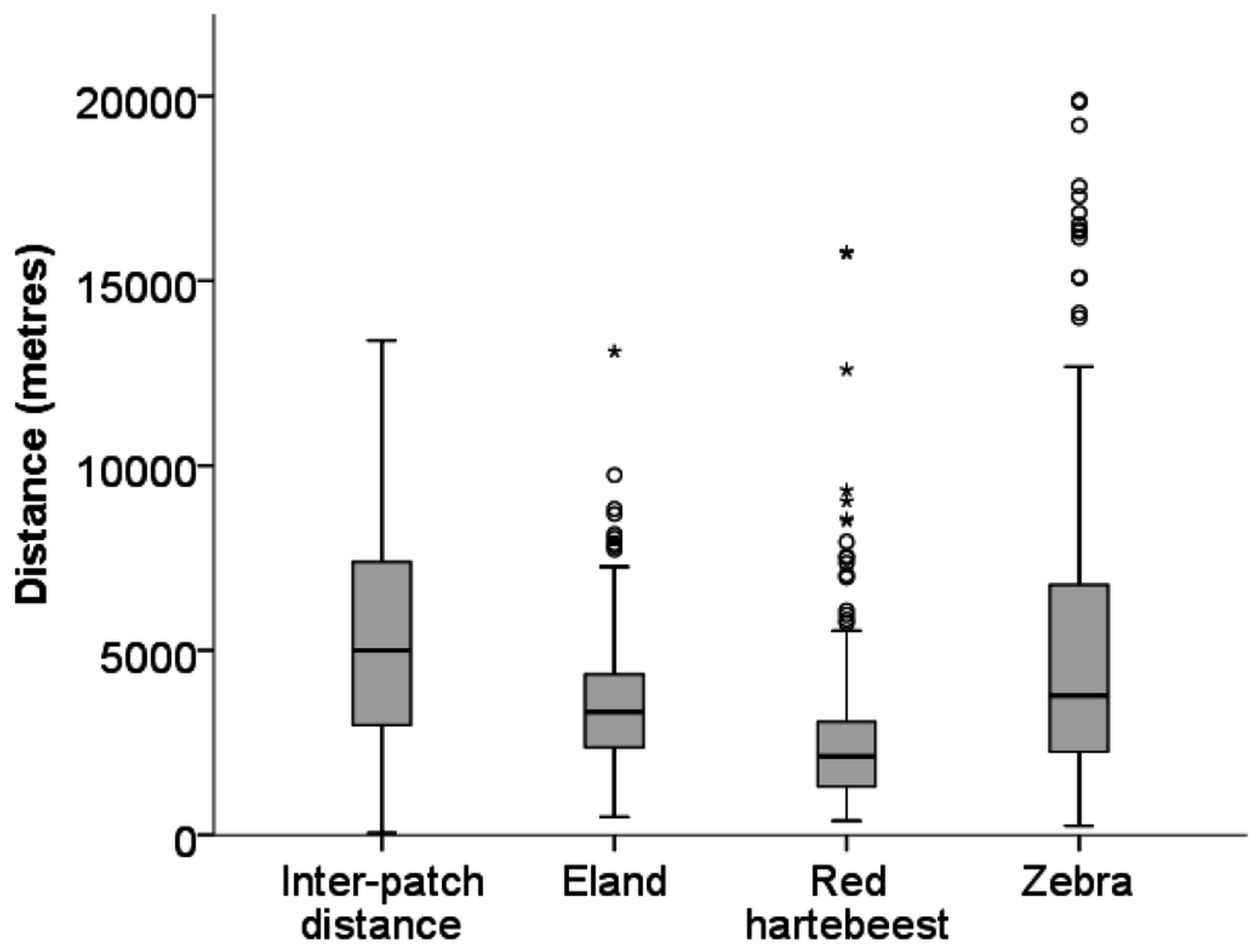




\section{Figure 3}

Directionality of movement of red hartebeest, eland and zebra in relation to visibility of the final locationin Mkambati Nature Reserve

Each point represents the $r$ and associated $p$-value from a Rayleigh test for a single 10-h walk to locations in different patches that were not visible from the start (left column), to locations in the same patch that were visible from the start (middle column), and to locations in different patches that were not visible from the start (right column). Data are shown for eland $(A, B, C)$, hartebeest $(D, E, F)$ and zebra $(G, H, I)$. 

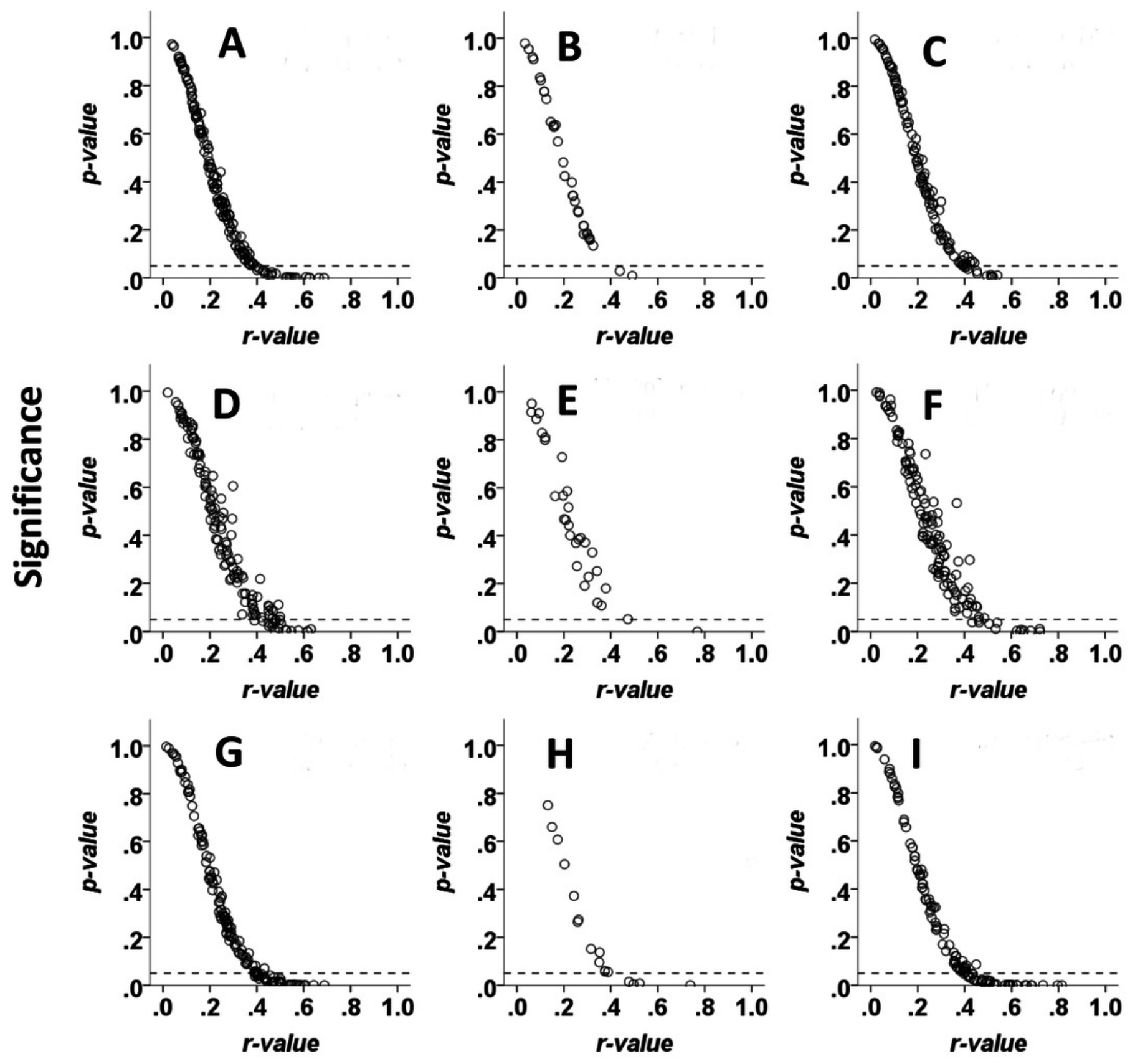

Directionality 


\section{Figure 4}

Mean step length of search movement outcomes and patch visibility classes for three herbivore species in Mkambati Nature Reserve

The relationship of A) search movement outcome (success) and B) patch visibility movement classes with mean step length of zebra, red hartebeest and eland studied in Mkambati Nature Reserve. Error bars indicate $95 \% \mathrm{Cl}$.
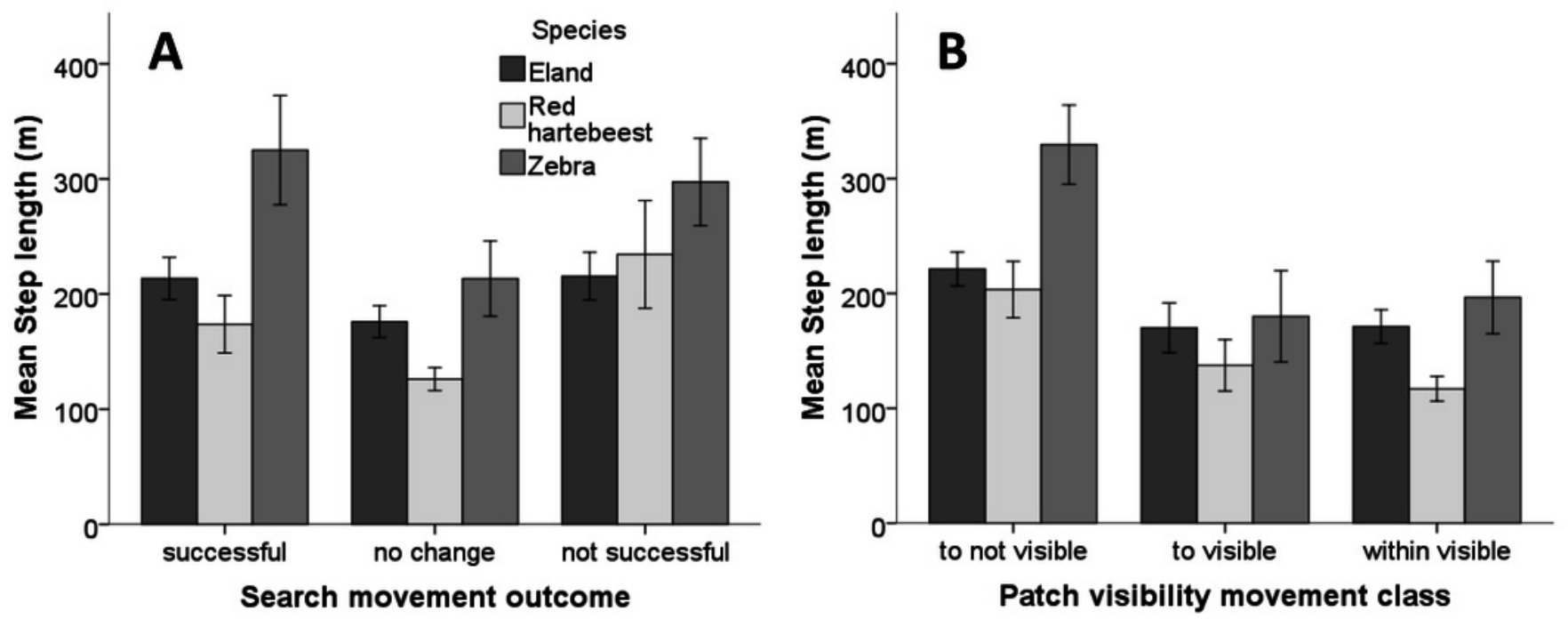


\section{Table $\mathbf{1}$ (on next page)}

The results of the pairwise comparisons between species, visibility movement class and search movement outcome 


\begin{tabular}{lcccc}
\hline \multicolumn{1}{c}{ Factor } & $\begin{array}{c}\text { Mean } \\
\text { difference }\end{array}$ & $\begin{array}{c}\text { Std. } \\
\text { Error }\end{array}$ & df & Sig. \\
\hline Species & & & & \\
Eland vs Red hartebeest & 30.505 & 24.531 & 17.737 & 0.69 \\
Eland vs Zebra & -64.331 & 25.029 & 16.69 & 0.06 \\
Red hartebeest * Zebra & -94.835 & 25.068 & 16.497 & $\mathbf{0 . 0 0 5}^{* *}$ \\
\hline Search movement outcome & & & & \\
Successful vs no change & 40.801 & 17.202 & 880.753 & 0.054 \\
Successful vs not successful & 2.367 & 12.681 & 874.701 & 1 \\
no change vs not successful & -38.434 & 17.094 & 879.703 & 0.074 \\
\hline Visibility movement class & & & & \\
to not visible vs to visible & 89.509 & 16.214 & 873.165 & $<\mathbf{0 . 0 0 0 5 * * *}$ \\
to not visible vs within visible & 54.408 & 15.837 & 877.081 & $\mathbf{0 . 0 0 2 * *}$ \\
to visible vs within visible & -35.102 & 22.758 & 881.966 & 0.37 \\
\hline
\end{tabular}

Significance: $<0.05^{*} ;<0.005^{* *} ; 0.0005^{* * *}$

1 